\title{
Capacity Utilisation and Performance at Railway Stations
}

\author{
John Armstrong a,b,1, John Preston ${ }^{\text {a }}$ \\ a Transportation Research Group, Faculty of Engineering and the Environment, \\ Southampton Boldrewood Innovation Campus, University of Southampton \\ Burgess Road, Southampton SO16 7QF, UK \\ b Arup, 13 Fitzroy Street, London W1T 4BQ, UK \\ ${ }^{1}$ E-mail: j.armstrong@ soton.ac.uk, Phone: +44 (0) 2380599575
}

\begin{abstract}
As traffic levels increase on railways in Britain and elsewhere, improved understanding of the trade-offs between capacity provision/utilisation and service quality is increasingly important, as Infrastructure Managers and Railway Undertakings seek to maximise capacity provision without an unacceptable loss of service reliability and punctuality. This is particularly true of the stations and junctions forming the nodes of railway networks, as they tend to be the capacity bottlenecks, and the relationships between capacity utilisation and performance are less well understood for nodes than for their intermediate links. Following on from initial work undertaken for the OCCASION project on the calculation of nodal Capacity Utilisation Indices, and on the application of the techniques developed for OCCASION to the recalibration of the Capacity Charge element of the Track Access Charges on Britain's railways, one of the objectives of the DITTO Rail Systems project is the further investigation of the relationship(s) between capacity utilisation and performance, as indicated by levels of congestion-related reactionary delay, at railway stations and junctions. Historic timetable and delay data for selected stations have been used to investigate these relationships, which take the expected form and tend to suggest lower maximum capacity utilisation levels for stations than for the links between them. Work is ongoing to develop these datasets and relationships further, and to identify suitable capacity utilisation upper limit values.
\end{abstract}

\section{Keywords}

Railways, Junctions, Stations, Capacity Utilisation, Performance

\section{Introduction}

Demand for rail transport in Britain is increasing rapidly, while the railway infrastructure is expanding slowly. This requires the railway industry to make the best possible use of available capacity, typically by running additional trains on existing infrastructure, while seeking to maintain acceptable levels of performance, i.e. punctuality, and, particularly, safety. This challenge is particularly pertinent to the network nodes - junctions and stations - that tend to form the capacity bottlenecks on the system, and for which the trade-offs between capacity utilisation and performance are more complex and less well-understood than for the plain line links between them. This paper describes work being undertaken to investigate the relationships between capacity utilisation and performance at nodes, as part of the research project 'Developing Integrated Tools To Optimise Rail Systems' (DITTO Rail Systems), funded by Britain's Rail Safety and Standards Board (RSSB).

Following this introduction, the background to the work is summarised, followed by a review of the underlying issues and previous work in this area. Next, the methodology 
adopted and the data used are described, the results and findings of the work to date are presented, and ongoing and planned further work is outlined. Finally, some conclusions are drawn, followed by a list of references.

\section{Background: Problem Statement and Objectives}

Passenger and freight rail traffic growth in Britain in recent decades has not been matched by an equivalent increase in network capacity, with the result that maintaining system performance is an increasing challenge. Train operators' desire to run additional services to meet growing demand can conflict with the Infrastructure Manager's (and the operators') objectives of maintaining service punctuality and reliability. Punctuality in Britain is monitored by means of the Public Performance Measure (PPM), a measure of the percentage of services arriving on time at their destinations. Furthermore, under Schedule 8 of their Track Access Agreements, Network Rail (the Infrastructure Manager (IM) of Britain's railways) and the Train Operating Companies (TOCs) are liable to pay one another compensation for delays for which they are responsible. Since the IM and the TOCs are completely separate organisations, potentially liable to net performance-related costs, there is an overall tendency towards conservatism, and a reluctance to operate additional services whose performance disbenefits might outweigh any service provision and capacity benefits.

This conservatism, and uncertainty surrounding reliable capacity utilisation limits, means that potentially valuable and beneficial train paths are not being used. The issue is particularly acute at railway stations and junctions, since they tend to form the capacity bottlenecks on a network, and, in contrast to their intermediate plain line links, no standard capacity utilisation upper limit values are available for them. Established methods of timetable stability analysis, such as the use of max-plus algebra (Goverde, 2015), have not yet been applied in Britain, for various reasons. Instead, continuing reliance has been placed upon simulation, and on empirical investigation of relationships between performance and various timetable and infrastructure characteristics. There is thus a need for a more generalised understanding of the relationships between capacity utilisation and performance at junctions and stations, if reliable capacity is to be maximised without repeated recourse to scenario-specific simulation; the work described in this paper seeks to address this need.

\section{Review}

The increasing demand for rail transport in Britain is reflected by the fact that annual passenger numbers recently exceeded the previous record number seen in the late 1940s (OECD, 2013), but on a much smaller network, comprising approximately half the 1948 route mileage (Capgemini, 2013). Although train performance and signalling and control technologies have improved significantly in the intervening period, the inevitable consequence is that the network is being used more intensively. There is no sign of these increases in demand abating, as confirmed by the Department for Transport (DfT, 2012):

Demand for rail travel is forecast to continue growing steadily for the next 20-30 years and many services will be full by the mid-2020s if we do not act now ... to provide much-needed additional rail capacity.

Additional capacity is being provided or planned for various sections of the network, in the form of new or upgraded infrastructure, including High Speed 2, the high-speed railway 
that will link London with the midlands and north of England, and beyond. It is nonetheless crucial to make the best possible use of existing (and new) infrastructure, thus maximising the beneficial exploitation of the potential capacity that is available.

Even defining capacity, however, is not necessarily straightforward. As noted by the International Union of Railways (UIC, 2004), it is difficult, if not impossible, to define a specific capacity value for any given section of railway:

capacity as such does not exist [and] railway infrastructure capacity depends on the way it is utilised.

Achievable capacity therefore depends not only upon infrastructure characteristics, including signalling systems, but also upon the performance characteristics and mix of trains using the route, the timetable in operation, and the target levels of reliability and punctuality to be achieved by the timetabled services. Capacity utilisation, or capacity consumption, measures (Pachl, 2015) provide an indication of the extent to which maximum theoretical capacity (for a given operating scenario) is being used.

As indicated above, on busy railway systems, two important capacity-related objectives are: (1) to maximise the number of trains that can be operated, subject to constraints imposed by service mix, stopping patterns, etc., while (2) maintaining acceptable levels of punctuality and reliability. As capacity utilisation levels increase, so, typically, does the capacity provided (although, as indicated above by UIC, capacity may be utilised in many different ways, with correspondingly varying levels of capacity provision).

However, as noted by Pachl (2009) and Martin (2015), as railway traffic flow increases, there is "increasing mutual hindrance of trains", with associated increases in waiting times, both scheduled (i.e. allowances, etc.) and unscheduled (i.e. delays). This decline in service quality is particularly pronounced when capacity utilisation exceeds recognised limits (UIC, 2004, 2013)

It can thus be seen that capacity provision can vary widely for a given level of capacity utilisation, and, conversely, different levels of capacity utilisation can occur for a single level of capacity provision, depending on how the capacity is provided, with implications for service quality. The situation was summarised as follows (Armstrong et al., 2011):

where capacity is scarce, the objective will typically be to maximise the capacity for the maximum level of capacity utilisation that is consistent with the provision of a stable, reliable quality of service. In order to achieve this, it is necessary to have measures of both provided capacity and capacity utilisation for all parts of the route or network in question, i.e. at nodes (junctions and stations) as well as links (sections of plain line between nodes). Well-defined capacity utilisation measures are currently available for links, but not generally for nodes.

The issue of nodes is particularly pertinent, since they tend to form the capacity bottlenecks on railway networks. The absence of nodal capacity utilisation measures was partly addressed by DITTO's predecessor project, OCCASION, which was focussed on nodal capacity constraints and included the extension of the Capacity Utilisation Index (CUI) approach (Gibson et al., 2002) from links to nodes, as described by Armstrong et al. (2012). The CUI approach is similar in principle to the UIC 406 method, but is based on planning rather than technical headways, and typically on longer route sections, consistent with the timetable planning process and operational rules (Network Rail, 2016) used in Britain. It was recognised at the conclusion of OCCASION that further work was needed 
to develop representative overall capacity utilisation measures for junctions and stations, and to identify suitable upper limits for nodal capacity utilisation, as already exist for links (UIC, 2004, 2013). Furthermore, the initial development of CUI measures for the stations and junctions in the OCCASION project study area, centred on Peterborough, on Britain's East Coast Main Line (ECML) between London and Edinburgh, did not include consideration or investigation of the relationship between these CUIs and performance.

This need for nodal capacity utilisation measurement techniques was endorsed by the fact that the UIC 406 update (UIC, 2013) was underway at the same time as OCCASION, with similar objectives, as described by Huber \& Herbacek (2013). In the same paper, the authors described ACCVA, the follow-up project to the UIC 406 update. The objectives of ACCVA include the identification of suitable upper limits for capacity utilisation at nodes, which is also one of the wider objectives of the DITTO project.

The tools and methods developed for OCCASION were applied to the Capacity Charge Recalibration (CCR) undertaken by Arup (2013) with support from the University of Southampton and Imperial College, London. For the purposes of the CCR, the relationships between capacity utilisation and performance (i.e. secondary delays due to high levels of railway traffic, recorded as Congestion-Related Reactionary Delay, or CRRD) on the links comprising Britain's national railway network were investigated and quantified to calculate the appropriate charges. Network nodes were excluded from the analysis, however.

. UIC 406-based approaches to the relationship between capacity and performance include those described by Landex (2011) and Libardo et al. (2011). Potential alternative techniques include industry approaches based on 'single channel systems', as described by Pachl (2009), the methods of Potthoff and their adaptations (Mussone and Calvo, 2013), and the use of approaches based on the sum of shortest headway reciprocals, originating with Vromans (2005) and subsequently advocated by Haith et al. (2014).

\section{Methodology and Data}

\subsection{Methodology}

The work undertaken to date in this area for the DITTO project relies primarily upon the continuing empirical investigation of relationships between capacity utilisation and performance. It builds upon the work done for the OCCASION and CCR projects by analysing capacity utilisation measures and performance data for junctions and stations.

The initial DITTO work used 2012 data generated for the CCR. CRRD data for Network Rail's London and North Eastern (LNE) Route was analysed and aggregated by location, with each station and junction for which at least 50 CRRD incidents were recorded in 2012 being categorised (e.g. major terminus, freight terminal, 2-track through station, etc.). Outlier locations with fewer than approximately one CRRD incident per week on average were thus excluded from the analysis, and the resulting dataset included $91.6 \%$ of all incidents recorded on the Route. The nodal categorisation, the number of nodes included in each category and the total number of delay incidents associated with each category, is summarised in Table 1. 
Table 1: Node categories, counts and CRRD incident counts

\begin{tabular}{|c|c|c|}
\hline Node Category & No. of Nodes & No. of CRRD Incidents \\
\hline Freight Terminal & 35 & 6,847 \\
\hline 2-track through Station & 15 & 2,393 \\
\hline Complex, Major Station & 11 & 18,887 \\
\hline Complex, Medium Station & 10 & 5,734 \\
\hline 2-track through Station with platform loop & 9 & 1,483 \\
\hline Complex, Minor Station & 8 & 5,721 \\
\hline 1-track Terminus & 8 & 1,535 \\
\hline 2-track through Station with bay platform & 7 & 934 \\
\hline $\begin{array}{l}\text { 2-track through Station with } 2 \text { platform } \\
\text { loops }\end{array}$ & 4 & 762 \\
\hline 2-track Terminus & 4 & 2,030 \\
\hline 1-track through Station with platform loop & 3 & 436 \\
\hline 2-track through station with junction & 3 & 507 \\
\hline 3-track Terminus & 2 & 892 \\
\hline 4-track Terminus & 2 & 330 \\
\hline $\begin{array}{l}\text { 2-track through Station with platform loop } \\
\text { and bay }\end{array}$ & 2 & 312 \\
\hline 4-track through station & 2 & 181 \\
\hline 2 side platforms, 4 tracks & 2 & 944 \\
\hline $\begin{array}{l}\text { 2-track through Station with } 2 \text { platform } \\
\text { loops and } 2 \text { bays }\end{array}$ & 1 & 97 \\
\hline $\begin{array}{l}\text { 2-track through Station with } 3 \text { platform } \\
\text { loops and } 1 \text { bay }\end{array}$ & 1 & 53 \\
\hline 2 side platforms, 4 tracks+ & 1 & 516 \\
\hline $\begin{array}{l}2 \text {-track through Station with platform loop } \\
\text { and } 2 \text { bays }\end{array}$ & 1 & 184 \\
\hline $\begin{array}{l}\text { 2-track through Station with } 2 \text { platform } \\
\text { loops and } 1 \text { bay }\end{array}$ & 1 & 60 \\
\hline $\begin{array}{l}\text { 2-track through Station with platform loop } \\
\text { and single platform }\end{array}$ & 1 & 75 \\
\hline 13 -track terminus & 1 & 220 \\
\hline $\begin{array}{l}\text { 2-track through station with freight } \\
\text { junction }\end{array}$ & 1 & 240 \\
\hline $\begin{array}{l}\text { 2-track through station with single } \\
\text { platform (some reversing) }\end{array}$ & 1 & 94 \\
\hline 3-track through Station & 1 & 383 \\
\hline 4-track through station (some reversing) & 1 & 235 \\
\hline 4-track through station with platform loop & 1 & 64 \\
\hline $\begin{array}{l}\text { 4-track through station with three } \\
\text { platforms }\end{array}$ & 1 & 68 \\
\hline 5-track Terminus & 1 & 127 \\
\hline 5-track through station & 1 & 54 \\
\hline 6-track Terminus & 1 & 108 \\
\hline 7-track Terminus & 1 & 419 \\
\hline 8-track Terminus & 1 & 104 \\
\hline $\begin{array}{l}\text { 2-track through Station with bay platform } \\
\text { out of use }\end{array}$ & 1 & 74 \\
\hline
\end{tabular}


The dataset containing the $91.6 \%$ of all incidents did not include any junctions, indicating that nodal CRRD occurs predominantly at stations, at least on this section of the national network. Freight terminals were excluded from the initial analysis and methodology development, for several reasons: they are less relevant than stations and junctions to network performance analysis, the details of train movements within them are not readily available, and train services tend to be less frequent than at stations and junctions. The initial development focus was therefore on the second entry in the table, 2-track through stations. The main study area for the DITTO project, between Alexandra Palace and Doncaster on the London - Edinburgh East Coast Main Line (ECML), including the Hertford Loop, does not include any stations in this category for which 2012 CRRD incidents occurred. Knaresborough station was therefore chosen in the 2-track through station category (albeit with a crossover) for the initial development of the methodology and tools. The rationale for its choice included the facts that it is had quite a large number of recorded 2012 CRRD incidents (174), and a mixture of originating, terminating and through passenger train services, including Empty Coaching Stock (ECS) movements that start or end at the station. The Knaresborough modelled area is shown in Figure 1.

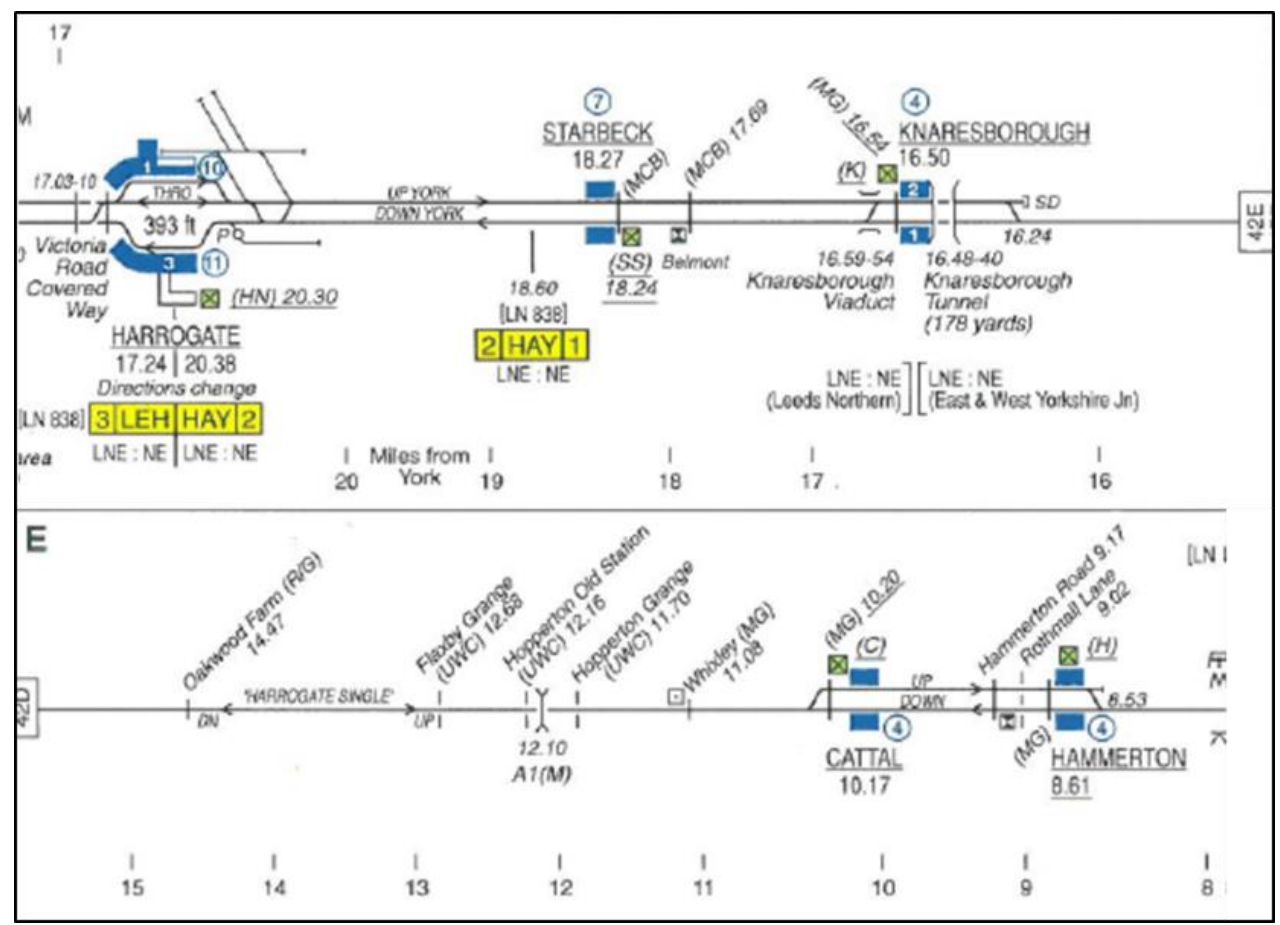

Figure 1: Knaresborough Model Area (source: TRACKmaps)

While the focus of the modelling interest was on the two platform tracks and the crossover to the west comprising the station area (and, to a lesser extent, the pair of switches to the east, where the line becomes single track), the modelled area was extended to include Starbeck and Harrogate to the west, and Cattal and Hammerton to the east. The main reason for this was to incorporate timetable information for the timing point locations (TIPLOCs) either side of Knaresborough, so that intermediate timings could be calculated for the 
switches adjacent to the station, in addition to the Knaresborough platform timings specified in the timetable data. For ECS moves between Harrogate and Knaresborough, timings are specified only for those two stations, and not for Starbeck, necessitating the inclusion of Harrogate in the model. The inclusion of Hammerton was not required for intermediate timing purposes, as Cattal's inclusion in the model met this need, but the station and the switches to its east were included in the model for pragmatic, short-term purposes, to facilitate the initial route searching process described below. The inclusion of these minor stations, whose platform numbers are not shown on the map extract, or specified in the Common Interface File (CIF) timetable data, had an additional benefit in the generalisation of the modelling process, as also described below. Infrastructure datasets representing the modelled area were prepared, describing the TIPLOCs and individual platforms and switches forming the nodes of the local network, and the links between them, including their length and directionality.

\subsection{Data Processing}

Having identified the area to be modelled initially and obtained the necessary data, train running information was extracted for services operating in the modelled area on the chosen date (Wednesday $14^{\text {th }}$ March 2012, as used in the CCR as a representative, 'neutral' date, unaffected by holidays or other 'non-standard' timetable features). The processes used for OCCASION and the CCR were based on tools previously developed for other purposes, and had a considerable amount of redundant functionality and were not particularly efficient. They were therefore re-written to meet the specific needs of DITTO, a possible future CCR exercise and other potential activities in this area.

The CIF file was searched for trains operating on the specified date and serving any or all of the stations between Hammerton and Harrogate inclusive. On finding such services, their Unique IDs (UIDs), headcodes and Service Codes were recorded, together with the TIPLOCs representing the stations found and the associated times and activities (i.e. Originate, Depart, Pass, Arrive or Terminate). This dataset was then processed to identify the detailed routeings and timings of trains through the modelled area.

As noted above, for some of the stations in the modelled area, the CIF data does not specify platform numbers, since there is no choice to be made in practice on a simple twotrack railway without bi-directional working. However, to accurately assess capacity utilisation at individual platforms, it is important to be able to identify which ones are being used by which trains (this was not an issue in OCCASION, as all platforms and tracks were specified in the more complex stations in the study area used, or in the CCR, since capacity utilisation was only being assessed on links). The route-finding process for DITTO was generalised to identify the platform numbers where they are not specified.

Having identified the detailed routeings, the timings at intermediate locations were interpolated on the basis of intermediate distances between the TIPLOCs for which times are specified (all intermediate events are assumed to be non-stopping 'Pass' movements, although this is not strictly true in the case of some unanticipated shunting movements, as described below). The interpolation of timings is a simplification, making no allowances for variations in speed and the effects of acceleration and deceleration, but it is a reasonable one for the purposes of capacity utilisation calculations, which are based more on the numbers of trains and their headways than on their detailed timings.

When the detailed routeings of all trains have been determined, the times and activities at each node in the modelled network were aggregated and sorted, and assigned to one of 24 one-hour and also one of eight three-hour timeslots labelled A-H, starting from 01:00. 
This approach reflects the experience gained from the CCR, where the data generated for one-hour timeslots was found to be considerably 'noisier' than that for three-hour slots. By starting and ending the three-hour slots at 01:00, this approach has the additional advantage of including the standard morning and evening peak periods of 07:00 - 10:00 and 16:0019:00 respectively. The first timeslot, from 01:00 to 04:00, is labelled $\mathrm{A}$, the morning and evening peak period timeslots are labelled $\mathrm{C}$ and $\mathrm{F}$ respectively, and the final slot, from 22:00 to 01:00, is labelled $\mathrm{H}$.

For each one- and three-hour time period, the capacity utilisation of each node is then determined by 'compressing' the sequence of train events to the appropriate minimum time intervals. The calculations distinguish between different event types and the associated variations between minimum headways/reoccupation times, dwell times and turnaround times. For each passing movement that occurs, the occupation time is increased by the minimum headway value. For trains arriving and then departing (i.e. normal passenger stops), the occupation time is augmented by the minimum dwell time, plus the minimum headway/platform reoccupation time. For trains that terminate and then either reverse or shunt to form a new, outgoing passenger service or ECS move, the occupation time is increased by the minimum turnaround time, plus the minimum headway/reoccupation time. No guidance is given on this matter in the updated edition of UIC 406 (UIC, 2013), and the example calculation included in the revised UIC 406 leaflet does not include any stopping trains; however, the compression of dwell and turnaround times to their minima is equivalent to the treatment of headways, and thus ensures a consistent approach. The situation at Knaresborough is complicated by the fact that Absolute Block signalling is used in the area, and standard minimum headway values are therefore not available. On the basis of the information provided in the Timetable Planning Rules and the timetable, the following values were adopted and applied:

- Minimum headway/reoccupation time -3 minutes

- Minimum dwell time - 1 minute

- Minimum turnaround time - 5 minutes

The timetable compression process was initially limited to the platforms, switches and crossings in the study area, but it will be extended to the intermediate links, as was the case for OCCASION and the CCR, in preparation for potential repetition of the latter work for the next industry Control Period, and to provide a richer overall dataset.

It was observed from the intermediate datasets that there were several terminating trains at Knaresborough Platform 2 without corresponding starting services, and, conversely, services starting from Platform 1 without terminating counterparts. It was concluded that the linking ECS/shunting moves from Platform 2 to Platform 1 were excluded from the CIF data, possibly because the moves take place entirely within a single TIPLOC (similar movements are explicitly timetabled for other stations, where the shunting moves take place via a loop or siding with a separate TIPLOC). This was rectified by creating 14 ECS/shunting moves, adding them to the CIF file, and re-running the capacity utilisation calculations. This situation is likely to be unusual, but it is an obstacle to the automated assessment of capacity utilisation using CIF data, and it would be helpful if all such moves were included explicitly in the timetable data.

The weekday CRRD data for Knaresborough was extracted and assigned to the nominated one- and three-hour timeslots using Excel; as described below, it is intended to automate this process to integrate capacity utilisation calculations and delay assignment. 


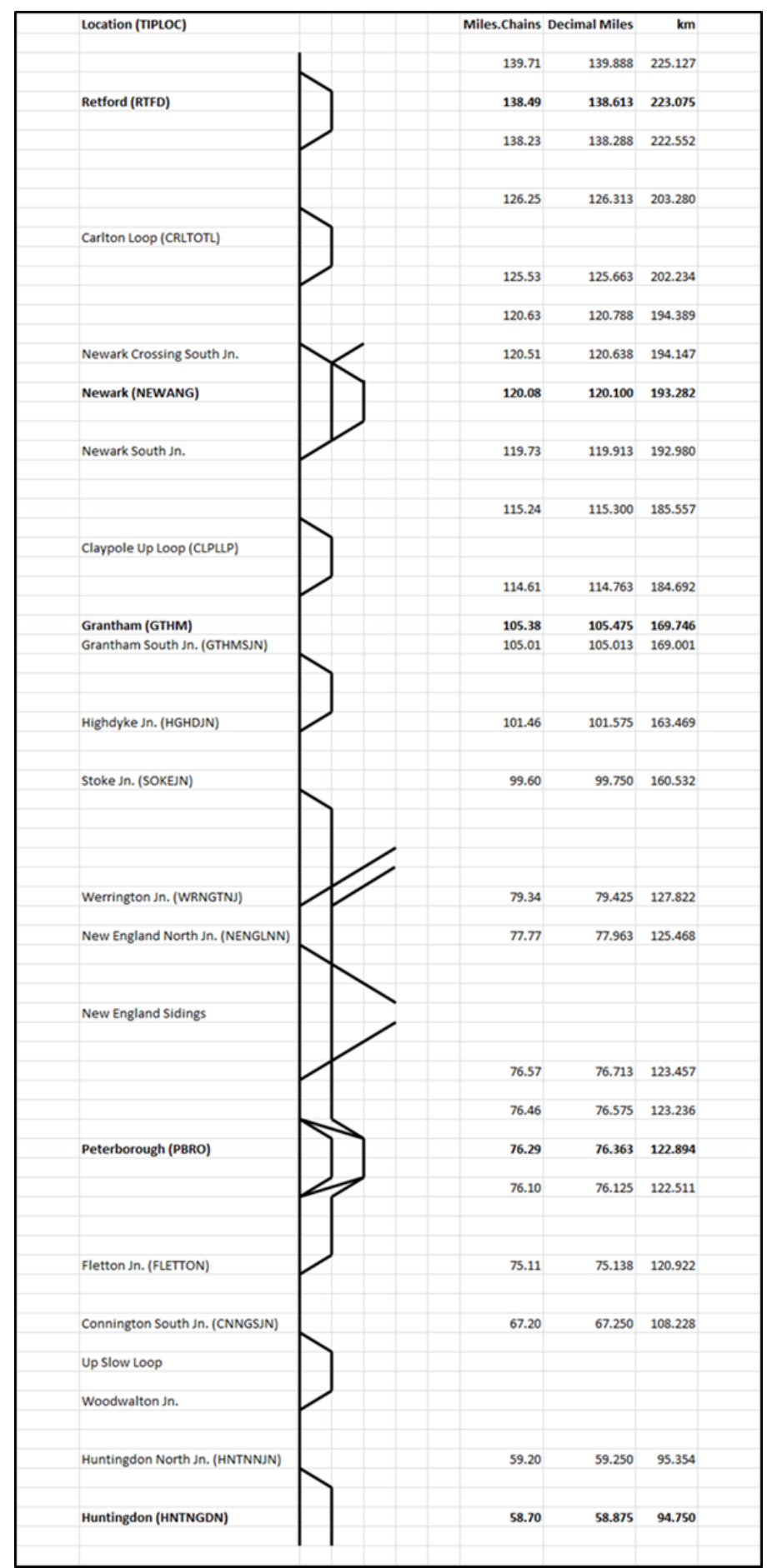

Figure 2: ECML DITTO Study Area (southbound only) 
Following the initial work on Knaresborough using 2012 data, the process was extended to the DITTO project's main study area, on the ECML between Alexandra Palace and Doncaster, focussing chiefly on southbound (or 'Up', i.e. towards London) train services on the section of the route between Grantham and Huntingdon, and particularly on Peterborough, a significant station and junction on this section of the route. The southbound route section is shown schematically in Figure 2, above.

The Peterborough-centred study area was chosen for several reasons: the same section of the network was used for the OCCASION project, and the project team was thus familiar with and had access to infrastructure data for the area (the Peterborough station layout underwent some changes in the intervening period, with the previous bay platform 1 being removed, a through platform (3) restored to use, and an island platform (6 and 7) being added on the west side of the station, so the infrastructure data was updated accordingly). Using a similar study area to the one used for OCCASION also provides a consistent 'analytical platform' and enables the results of the wider aspects of the DITTO Rail Systems project (Preston et al., 2017) to be compared with those obtained from the OCCASION work.

In addition to the infrastructure amendments, and to reflect their effects (and those of any changes to the timetable planning rules for the area) on performance and to bring the analysis up to date, more recent timetable and performance datasets were used for the analysis. Timetable data for the seven-month period from May 2015 was used, with the 'neutral date' of Wednesday $4^{\text {th }}$ November 2015 being chosen as the representative day for modelling in this case. Corresponding performance data was also obtained. The processes described above for Knaresborough were then repeated for the ECML study area; the results of both are presented in the following section.

\subsection{Data}

As noted above, data for the initial analysis was derived from the CCR work undertaken previously, and additional, up-to-date timetable and performance data was then obtained for the subsequent ECML-based analysis. This was facilitated by the increasing availability of open data in Britain's railway industry: CIF-format timetable data (used for the capacity utilisation calculations) and historic performance data (individual historic train delay records) are both now available from Network Rail's website. This represents a significant improvement in data availability in recent years, as these datasets had to be requested specifically for both the OCCASION and CCR projects.

As was previously the case, the Timetable Planning Rules (Network Rail, 2016), specifying minimum planning headways, minimum junction margins and minimum dwell and turnaround times at stations, are also available online.

For the purposes of building network models, some data is available online, in the form of Network Rail's Sectional Appendices, but this is supplemented by reference to other sources, including commercially-published track diagrams and electronic 'Five Mile Diagrams' available within the railway industry.

\section{Results and Findings}

The results and findings of the work to date are described below, first for the initial work on the Knaresborough area, and then for the stations on the ECML between Retford and Peterborough inclusive. 


\subsection{Knaresborough}

The calculated hourly (0-23) and three-hourly (A-H) CUI values for Knaresborough station platforms 1 and 2 are shown in Table 2, together with the corresponding annual CRRD minutes assigned to each platform. It can be seen that maximum capacity utilisation and delay minute values are predominantly found in the morning and evening peak periods for both the hourly and three-hourly (periods $\mathrm{C}$ and F) assignments.

Table 2: Knaresborough Station Capacity Utilisation and Delay Minutes

\begin{tabular}{|c|c|c|c|c|}
\hline \multirow{2}{*}{ Period } & \multicolumn{2}{|c|}{ Capacity Utilisation } & \multicolumn{2}{|c|}{ Annual CRRD Minutes } \\
\hline & Pl.1 & Pl.2 & PI.1 & PI.2 \\
\hline 0 & $0.0 \%$ & $0.0 \%$ & 0 & 0 \\
\hline 1 & $0.0 \%$ & $0.0 \%$ & 0 & 0 \\
\hline 2 & $0.0 \%$ & $0.0 \%$ & 0 & 0 \\
\hline 3 & $0.0 \%$ & $0.0 \%$ & 0 & 0 \\
\hline 4 & $0.0 \%$ & $0.0 \%$ & 0 & 0 \\
\hline 5 & $0.0 \%$ & $0.0 \%$ & 0 & 0 \\
\hline 6 & $4.2 \%$ & $20.0 \%$ & 0 & 22 \\
\hline 7 & $42.5 \%$ & $40.0 \%$ & 58 & 92 \\
\hline 8 & $20.0 \%$ & $20.0 \%$ & 25 & 19 \\
\hline 9 & $13.3 \%$ & $20.0 \%$ & 0 & 101 \\
\hline 10 & $20.0 \%$ & $20.0 \%$ & 14 & 0 \\
\hline 11 & $20.0 \%$ & $20.0 \%$ & 0 & 52 \\
\hline 12 & $20.0 \%$ & $20.0 \%$ & 0 & 23 \\
\hline 13 & $20.0 \%$ & $20.0 \%$ & 0 & 16 \\
\hline 14 & $20.0 \%$ & $20.0 \%$ & 0 & 7 \\
\hline 15 & $20.0 \%$ & $20.0 \%$ & 0 & 5 \\
\hline 16 & $20.0 \%$ & $20.0 \%$ & 4 & 19 \\
\hline 17 & $26.7 \%$ & $24.2 \%$ & 0 & 13 \\
\hline 18 & $20.0 \%$ & $42.5 \%$ & 90 & 23 \\
\hline 19 & $20.0 \%$ & $20.0 \%$ & 0 & 67 \\
\hline 20 & $6.7 \%$ & $6.7 \%$ & 0 & 9 \\
\hline 21 & $6.7 \%$ & $6.7 \%$ & 0 & 23 \\
\hline 22 & $5.0 \%$ & $20.0 \%$ & 0 & 0 \\
\hline 23 & $0.0 \%$ & $0.0 \%$ & 0 & 0 \\
\hline A & $0.0 \%$ & $0.0 \%$ & 0 & 0 \\
\hline B & $2.8 \%$ & $6.7 \%$ & 0 & 22 \\
\hline $\mathrm{C}$ & $25.3 \%$ & $26.7 \%$ & 83 & 212 \\
\hline D & $20.0 \%$ & $20.0 \%$ & 14 & 75 \\
\hline E & $20.0 \%$ & $20.0 \%$ & 0 & 28 \\
\hline F & $22.2 \%$ & $28.9 \%$ & 94 & 55 \\
\hline G & $11.1 \%$ & $11.1 \%$ & 0 & 99 \\
\hline $\mathrm{H}$ & $1.7 \%$ & $6.7 \%$ & 0 & 0 \\
\hline
\end{tabular}

The three-hourly capacity utilisation and CRRD results for Platforms 1 and 2 are plotted in Figures 3 and 4 respectively. 


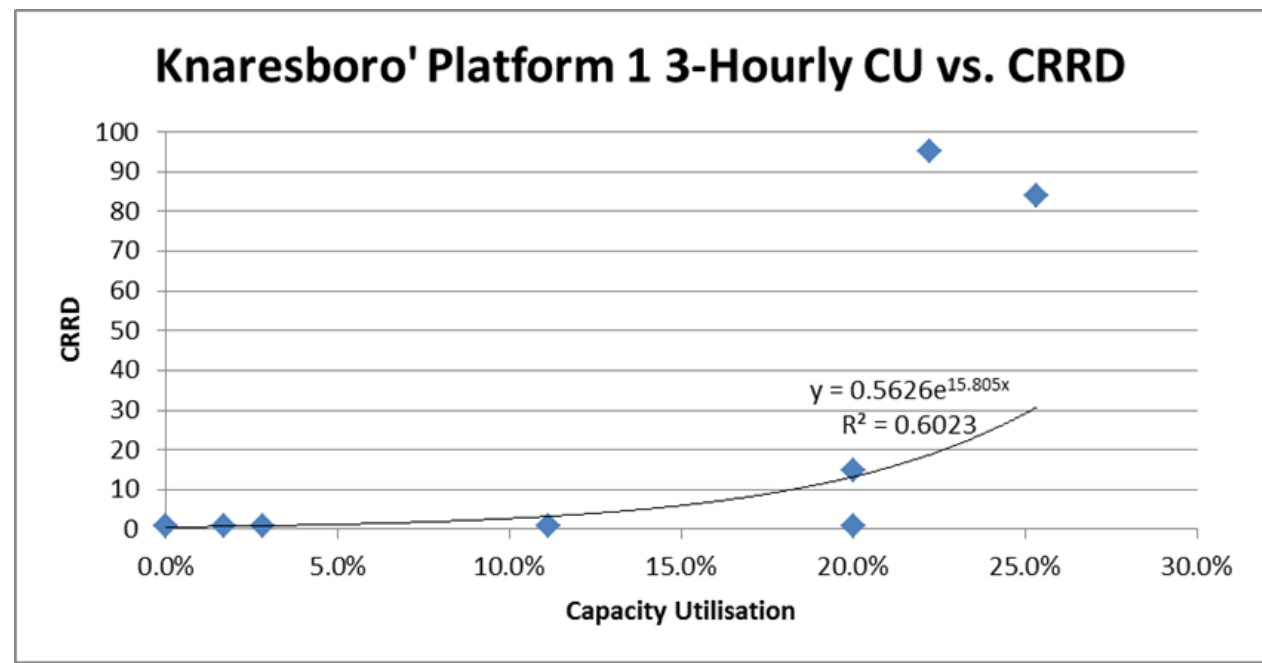

Figure 3: CRRD/CUI relationship for Knaresborough Platform 1

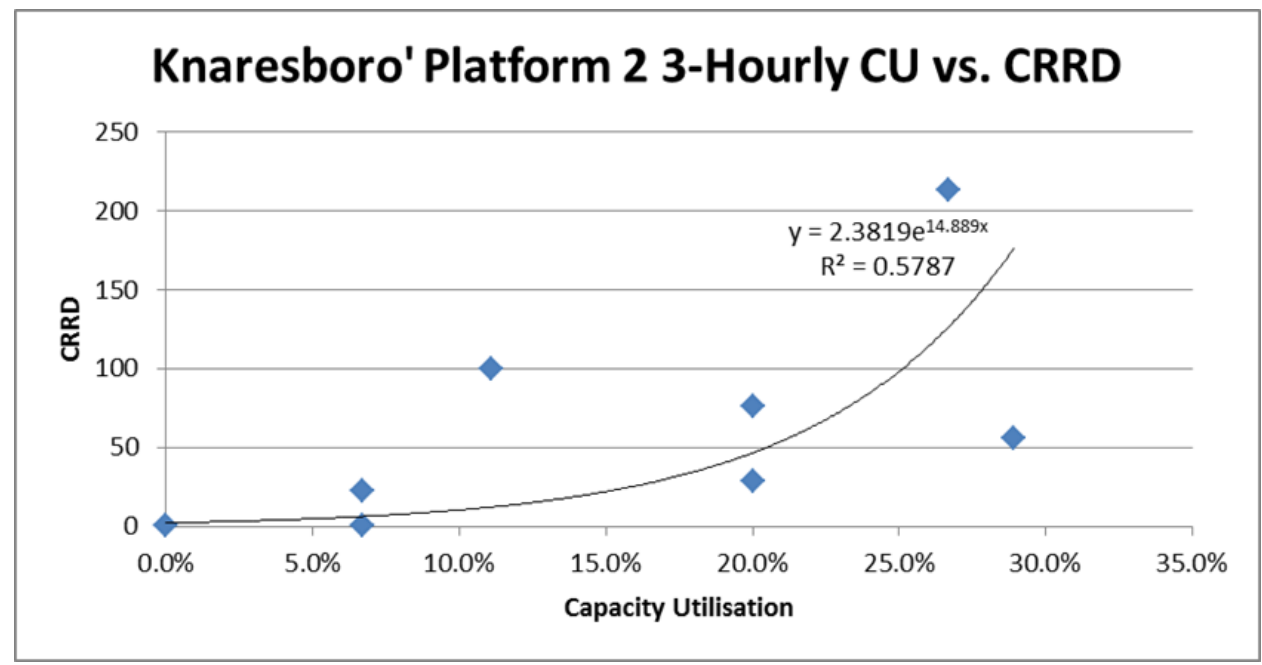

Figure 4: CRRD/CUI relationship for Knaresborough Platform 2

For both platforms, the expected exponential relationship between capacity utilisation and delay can be seen, although the low $\mathrm{R}^{2}$ values suggest that other factors also affect performance. The station's proximity to the single-track section to the east may be a factor, reflected in the slightly lower $\mathrm{R}^{2}$ value and higher CRRD values for eastbound Platform 2 . In both cases, CRRD increases quite sharply at relatively low CUI values.

\subsection{ECML: Grantham - Peterborough}

An equivalent analysis was undertaken for the stations on the ECML between Retford and Peterborough inclusive, using the updated timetable and CRRD data for southbound 
services only. The results are not tabulated due to space constraints, but layout diagrams and relevant statistical outputs for each station are shown in Figures 5-16 inclusive.

Figure 5 shows the layout of Retford station (southbound lines are shown running from right to left), and Figure 6 shows the relationship between capacity utilisation and aggregate CRRD on the through, Up Fast line, as indicated by the data. Figures 7 and 8 show the equivalent results for the Up platform loop (Platform 1) and switch 2242, where the platform loop re-joins the Up Fast line.

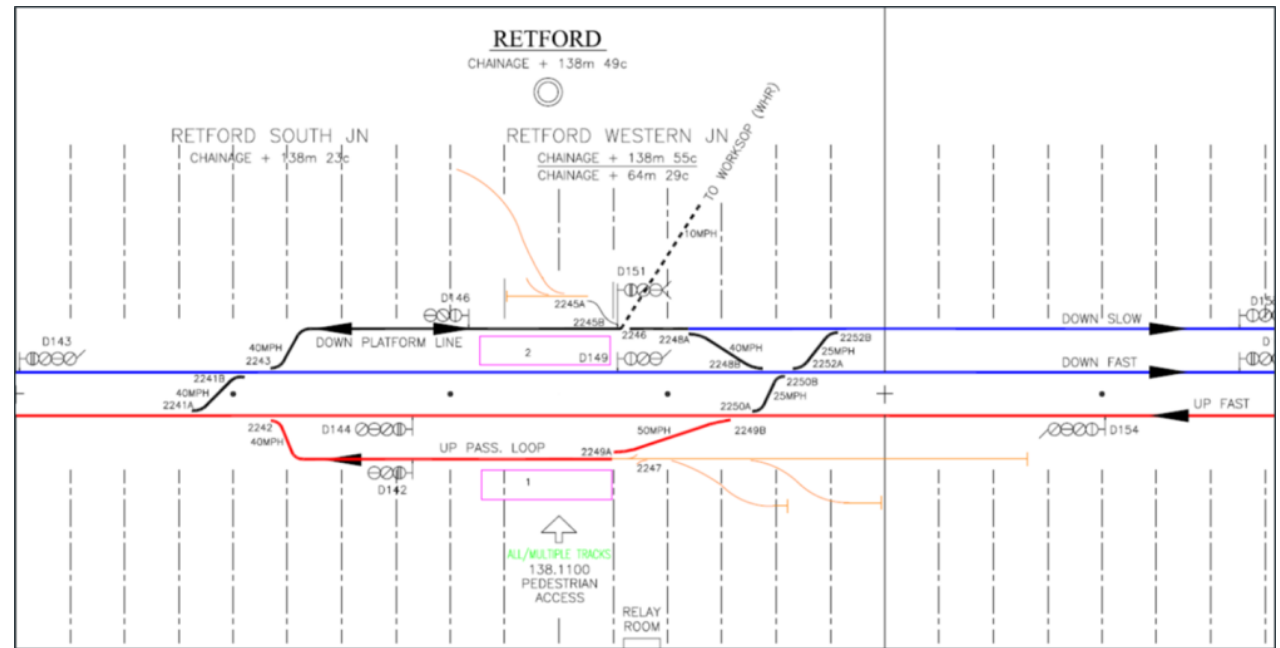

Figure 5: Retford station layout

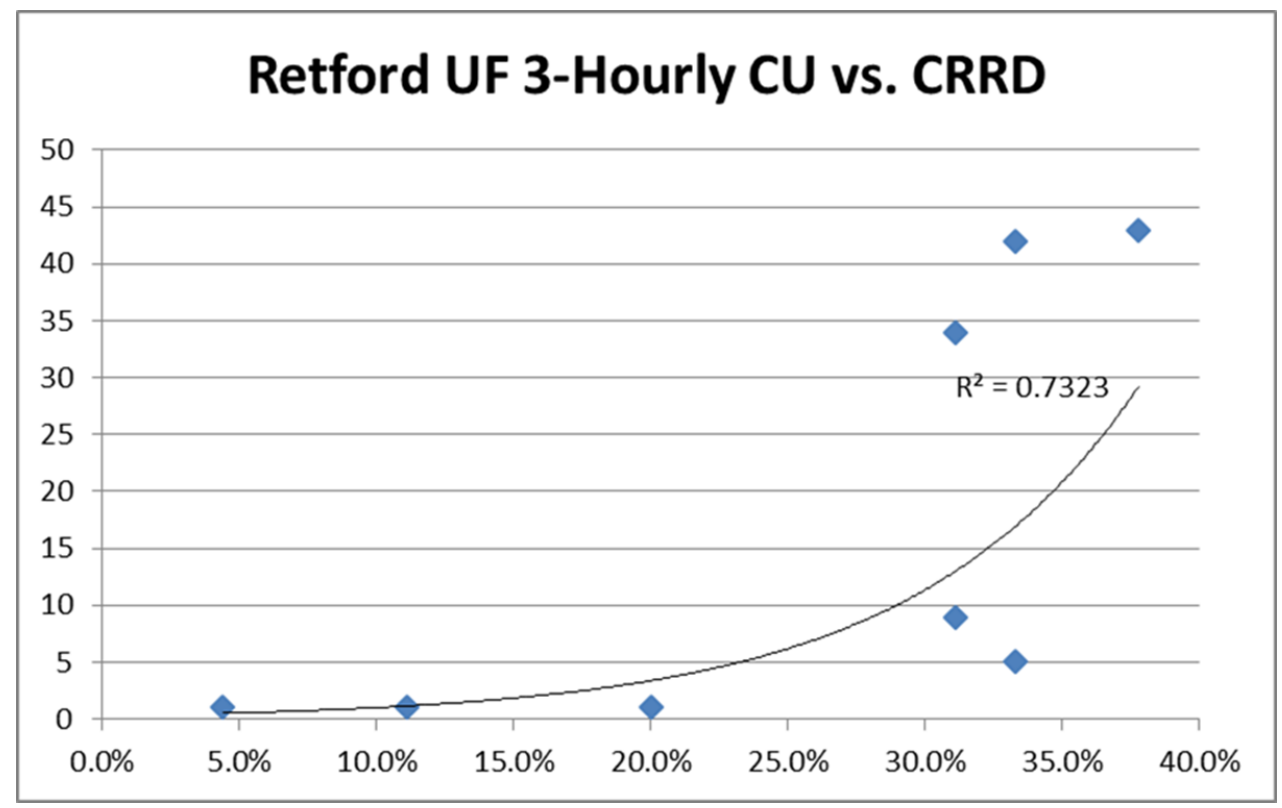

Figure 6: CRRD/CUI relationship for Retford Up Fast line 


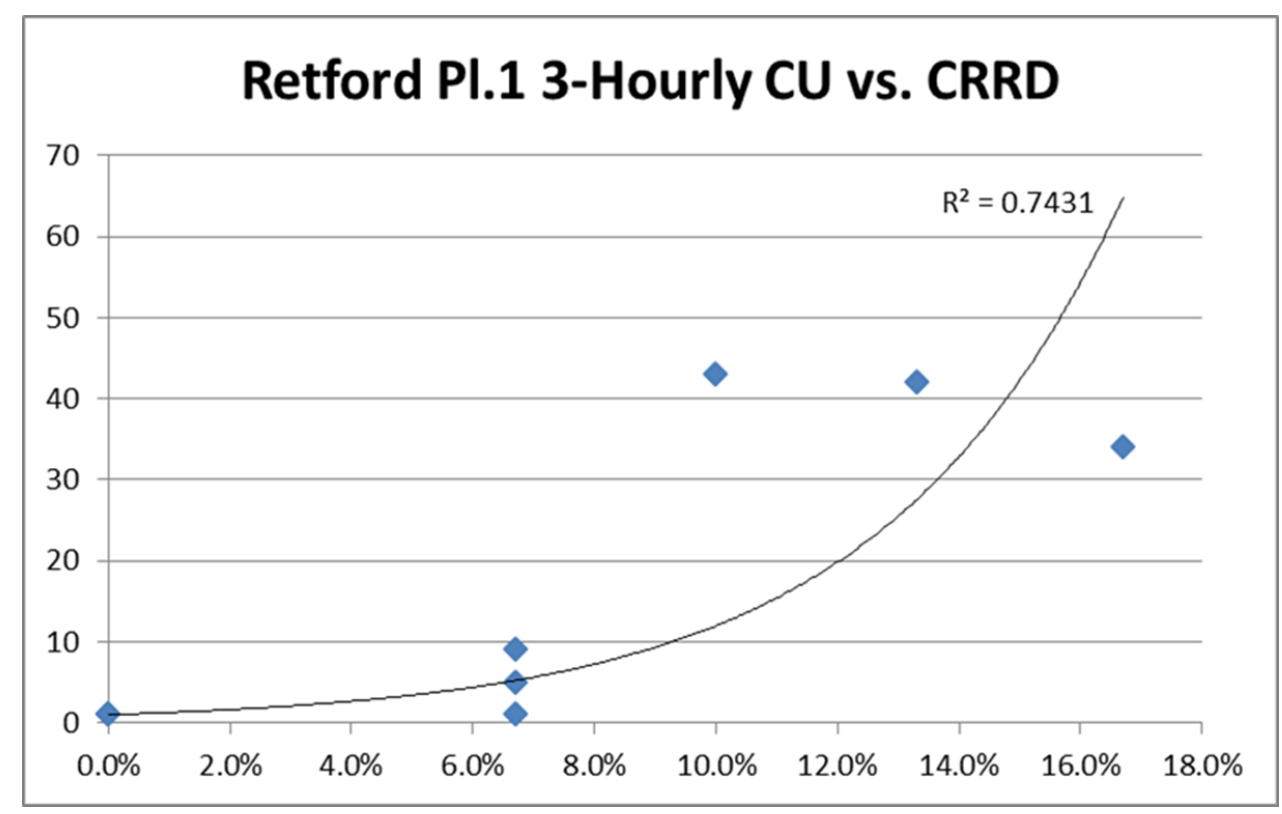

Figure 7: CRRD/CUI relationship for Retford Up Passenger Loop (Platform 1)

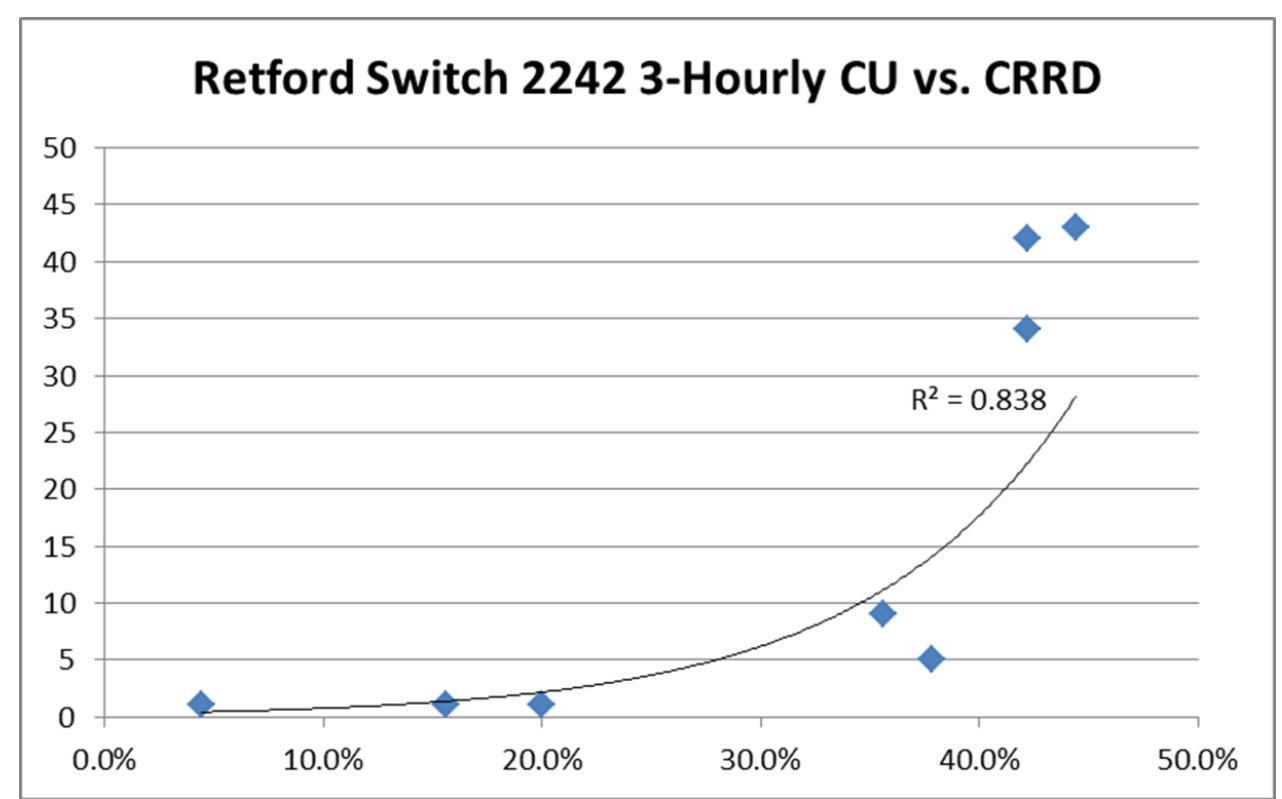

Figure 8: CRRD/CUI relationship for Retford converging switch 2242

It can be seen that the data points for the Up Fast line and switch 2242, in particular, take the expected form, and that all three fitted exponential curves have quite high $\mathrm{R}^{2}$ values. The CUI values for the platform loop, however, are low, and are unlikely to be determining 
overall performance and levels of CRRD. The data for the converging switch includes the largest CUI values of the three datasets, and also the highest $\mathrm{R}^{2}$ value. This is intuitively correct, as the switch will be carrying the largest number of trains, from both upstream links, and trains using it will be the most susceptible to congestion-related delay.

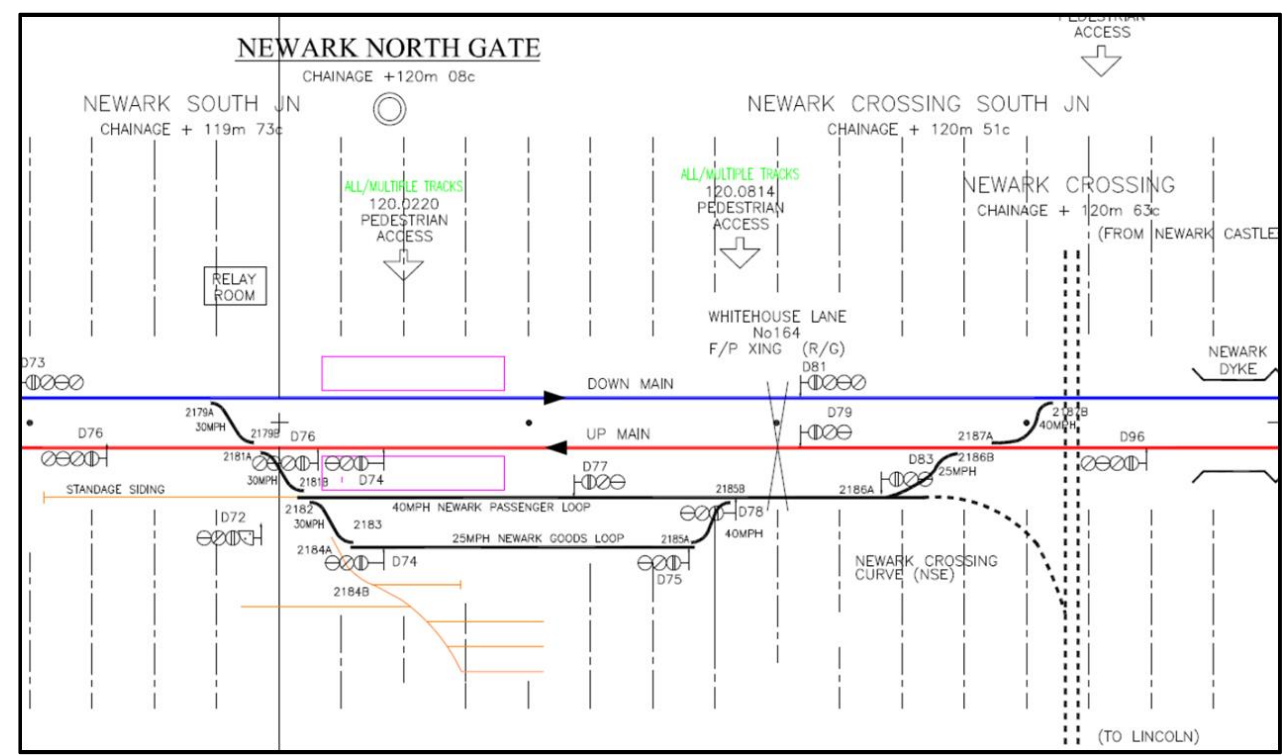

Figure 9: Newark North Gate station layout

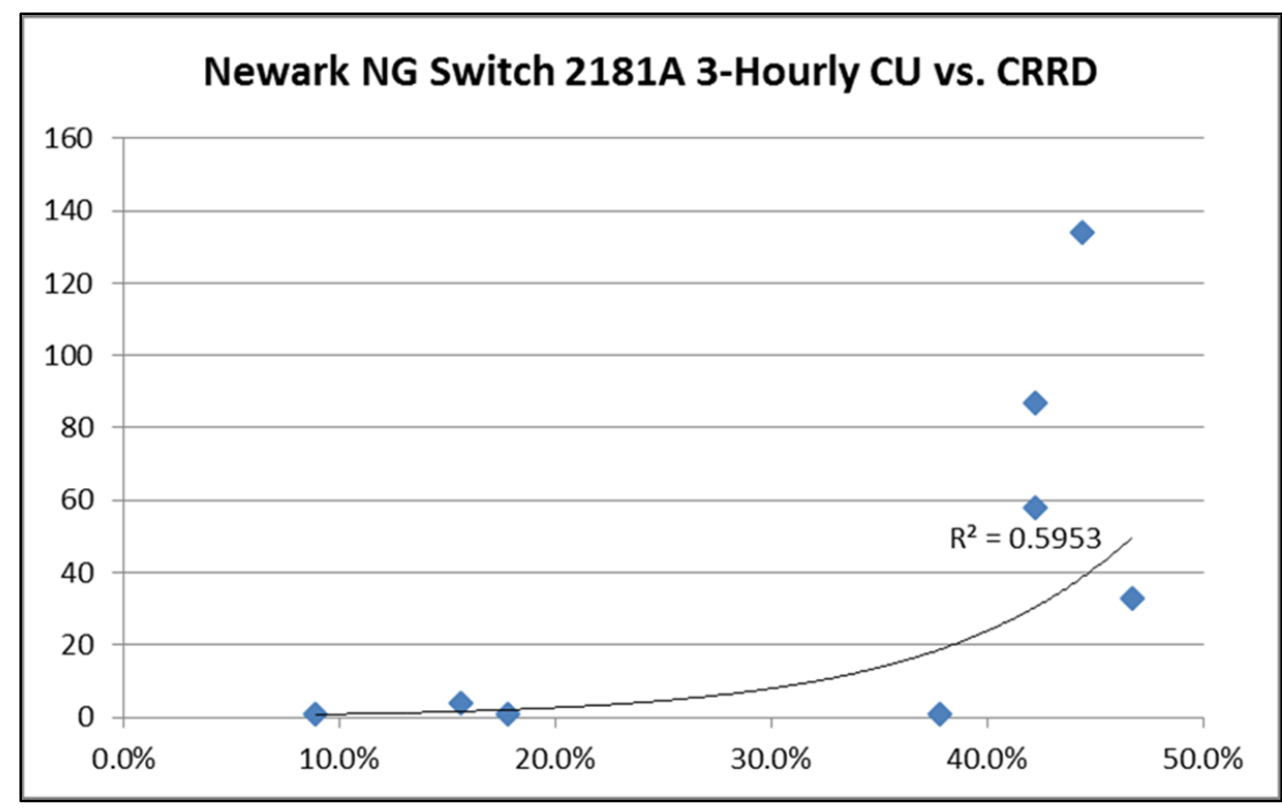

Figure 10: CRRD/CUI relationship for Newark North Gate merging switch 2181A 
The layout and CRRD/CUI relationship for Newark North Gate station are shown in Figures 9 and 10. Again, the relationship was investigated for the Up Main line, platform loop and converging switch, and the data for switch 2181A was found to have the highest level of correlation, at 0.5953 , as shown in Figure 10 (the equivalent $\mathrm{R}^{2}$ value for the Up Main track was 0.5416 ). The data has a similar pattern to that for the equivalent switch at Retford, although the Newark North Gate $\mathrm{R}^{2}$ value is considerably lower.

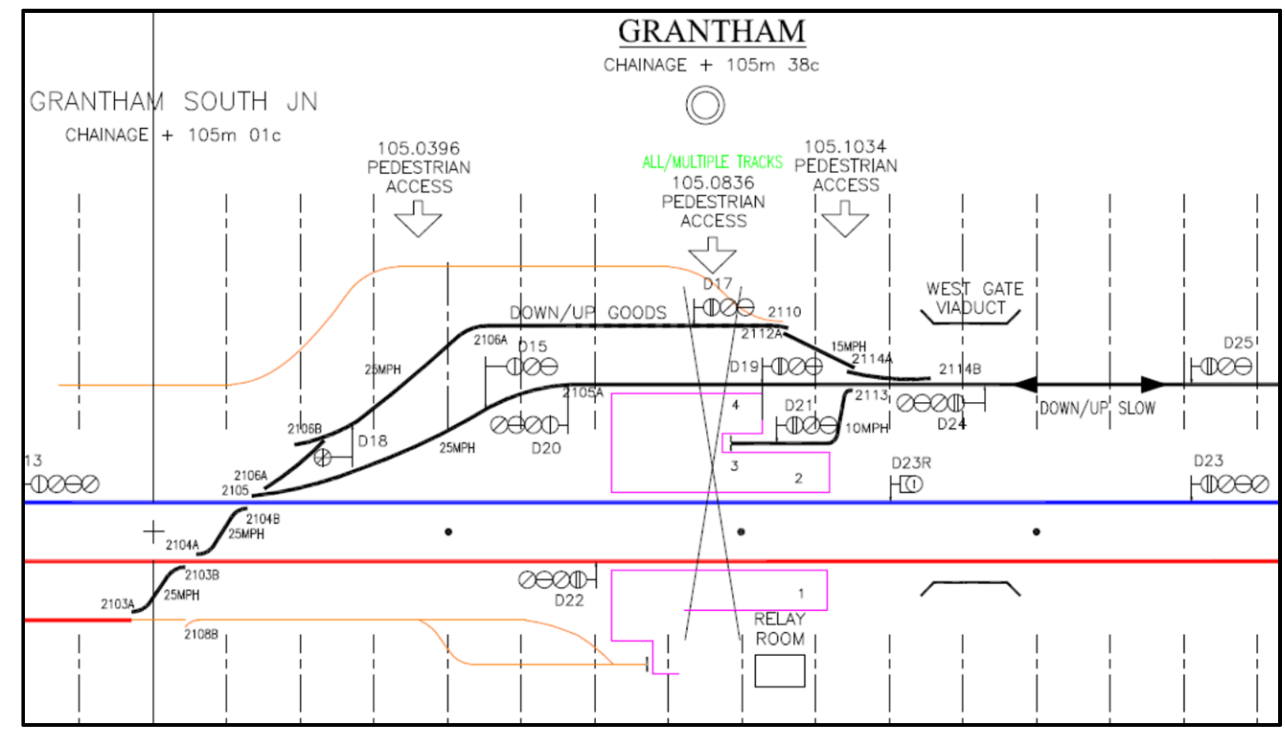

Figure 11: Grantham station layout

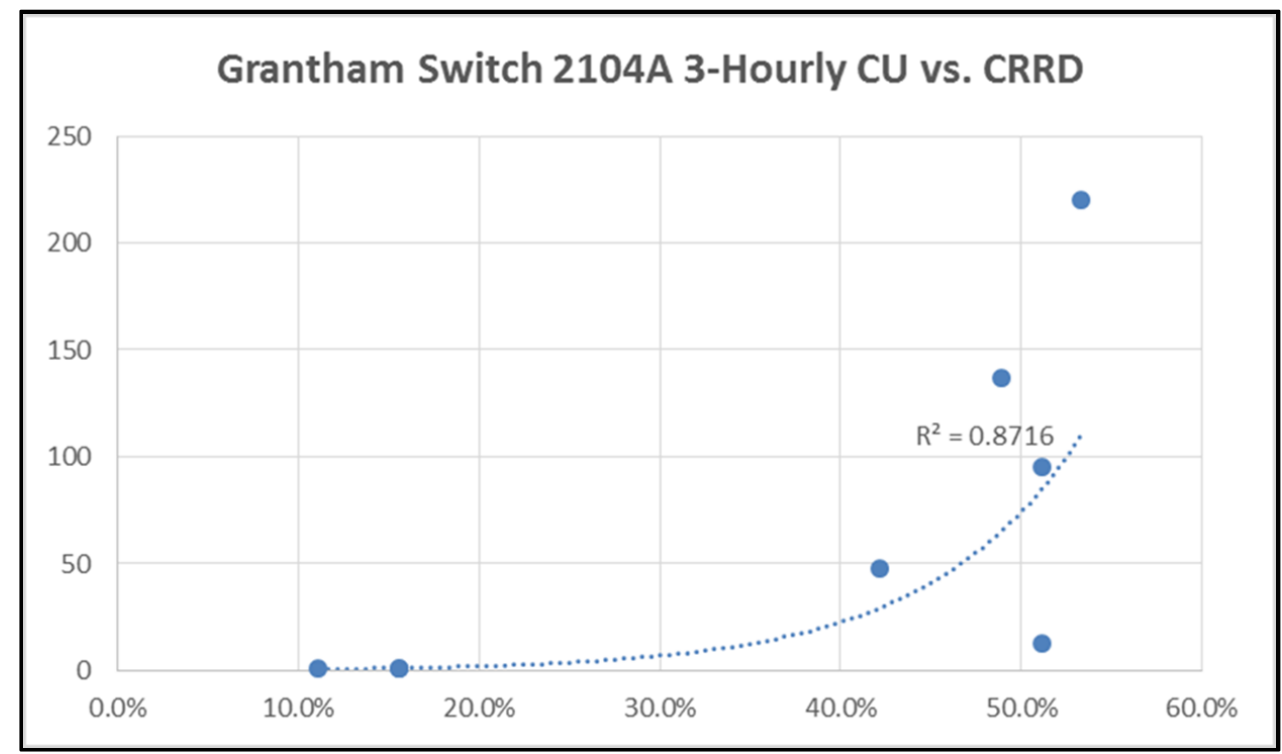

Figure 12: CRRD/CUI relationship for Grantham converging switch 2104A 
The layout and CRRD/CUI relationship for Grantham station are shown in Figures 11 and 12. Again, the relationship was investigated for the Up Fast line (platform 1), Down/Up Slow line (platform 4) and their converging switch 2104A. The highest correlation (0.9136) was obtained for the Down/Up Slow line, but, as for the platform loops at Retford and Newark North Gate, the CUI values were very low. The next-highest $\mathrm{R}^{2}$ value was 0.8716 , for the switch, shown, slightly higher than for the Up Fast line (0.8204).

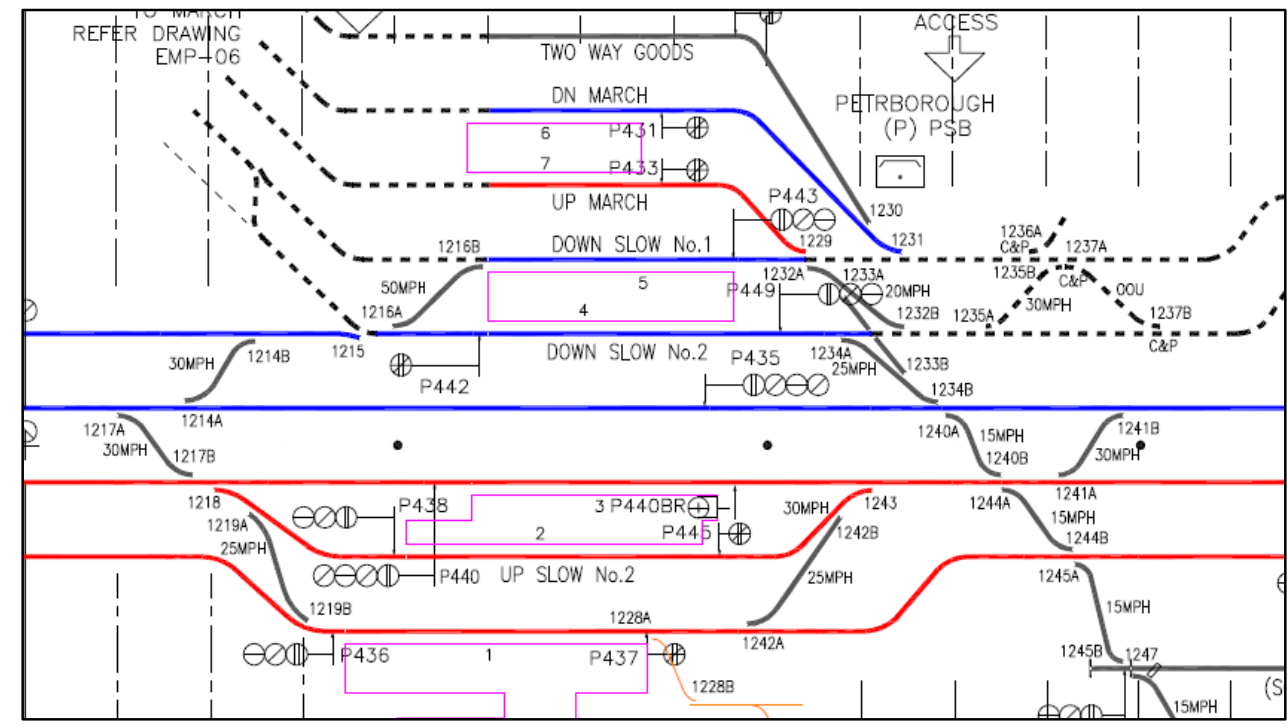

Figure 13: Peterborough station layout

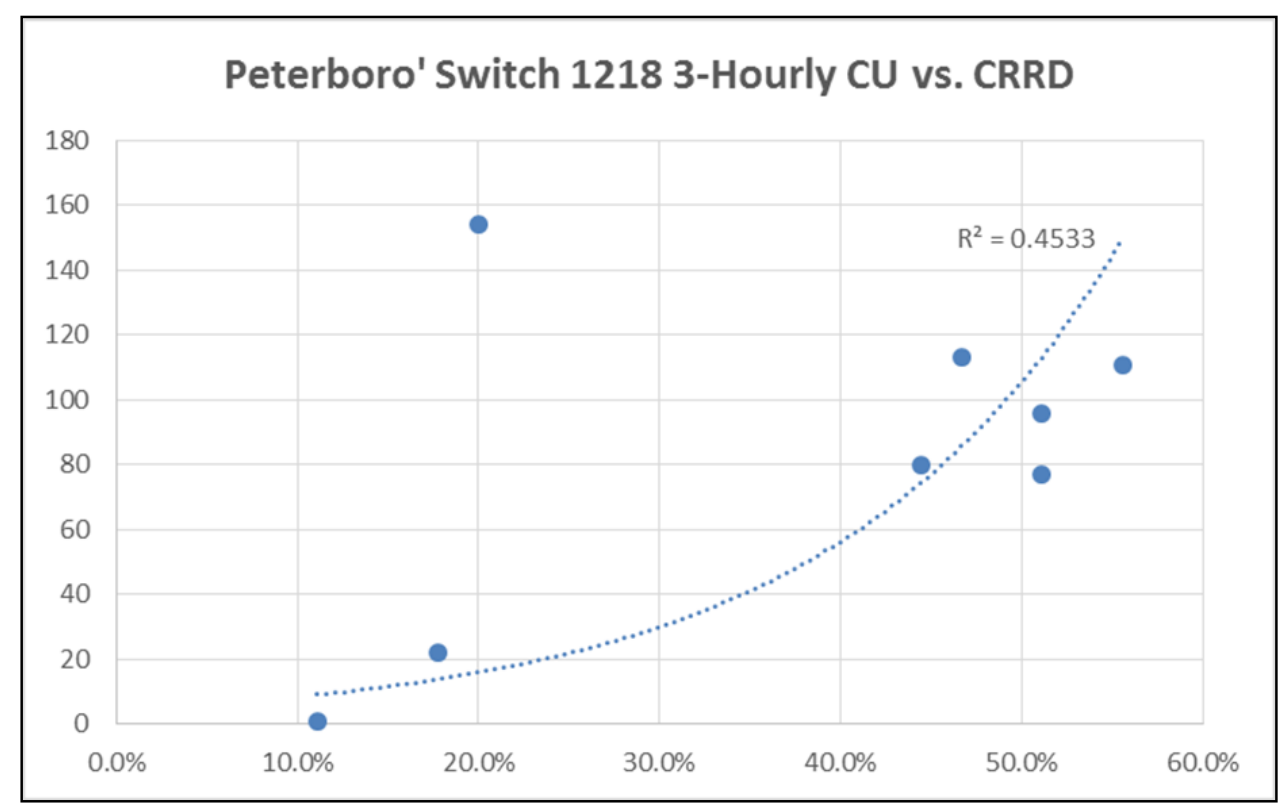

Figure 14: Aggregate CRRD/CUI relationship for Peterborough switch 1218 
Figures 13-16 show the Peterborough station layout and selected CRRD/CUI analysis results. Initial analysis using aggregate southbound delay data produced relatively low $\mathrm{R}^{2}$ values across the different tracks/platforms and converging switch 1218 (Figure 14). This reflects the station's relative complexity, and the allocation of southbound train movements and delays to platforms 4-7 (top of Figure 13), as well as platforms 1-3.

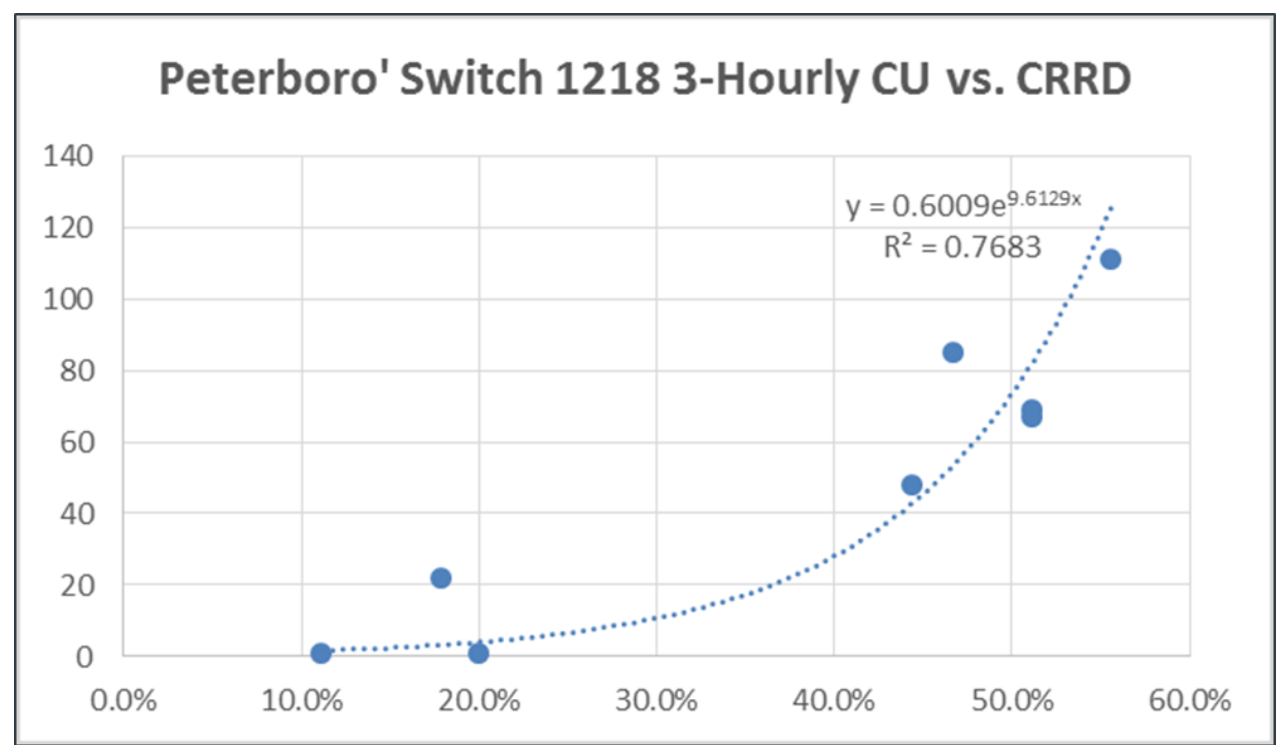

Figure 15: Disaggregate CRRD/CUI relationship for Peterborough switch 1218 (including delays allocated to Platforms 1-3)

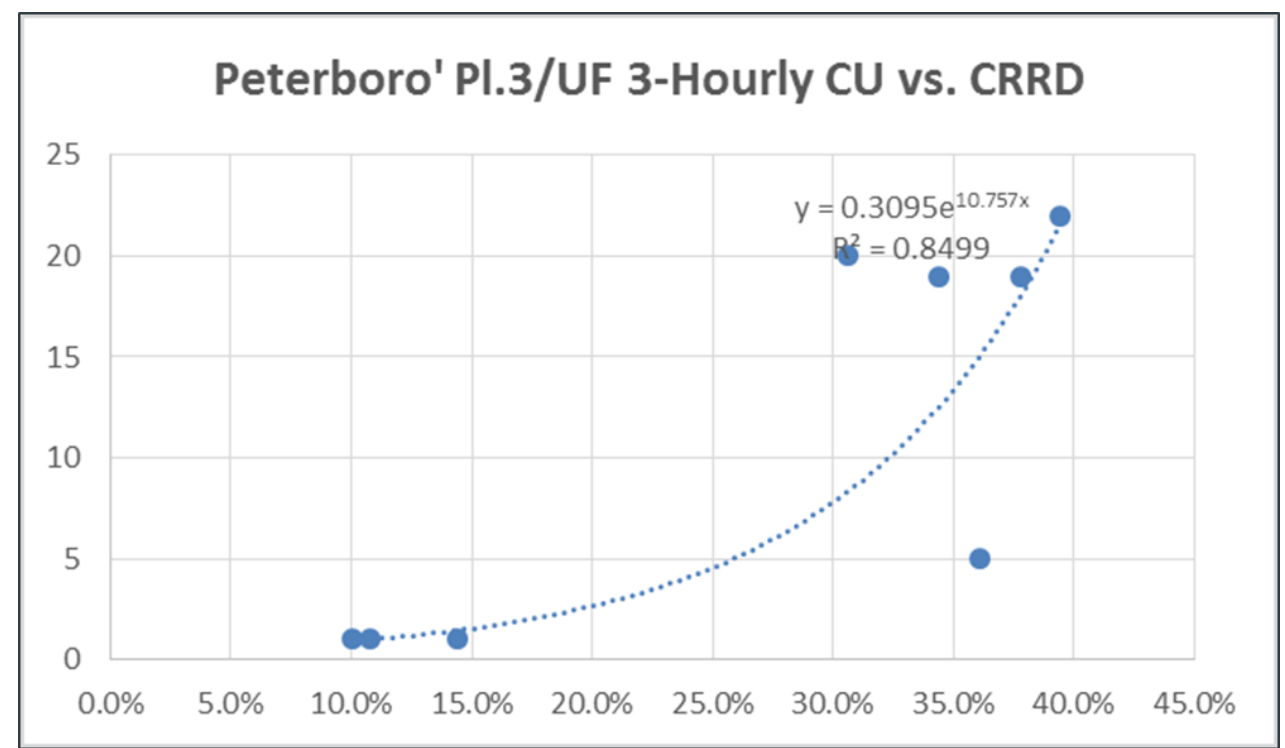

Figure 16: disaggregate CRRD/CUI relationship for Peterborough platform 3/Up Fast 
The delay data was therefore disaggregated by track/platform, which had the further advantage of removing the outlying value that can be seen in Figure 14, associated with a large delay to a freight train passing platforms 4-7. The effect of disaggregating the data can be seen by comparing Figures 14 and 15 and the associated $\mathrm{R}^{2}$ values. For the disaggregated data, the highest level of correlation was obtained for the Up Fast line (platform 3), with an $\mathrm{R}^{2}$ value of almost 0.85 .

\subsection{Findings}

It can be seen that, for the selected stations, the relationship between historic capacity utilisation and congestion-related reactionary delay data takes the expected exponential (or similar) form, and there appears to be some consistency in the capacity utilisation levels at which congestion-related reactionary delay starts to increase markedly. These values also appear to be lower than those recommended for plain line sections, i.e. between $60 \%$ and $75 \%$ for a three-hour period on a mixed-traffic railway, according to the original 2004 UIC 406 leaflet (the actual difference is greater than this, since the CUI approach compresses the timetable to the minimum planning headway, greater than the technical headway, and thus produces a higher capacity utilisation value). This is consistent with the relative complexity and variability of train movements and interactions at stations (and, to a lesser extent, junctions), and with the consensus that these nodes form the bottlenecks in the overall network. Further data and analysis are required to develop this understanding further, generalise the relationships (if and where possible) and identify appropriate upper limits for capacity utilisation at nodes.

\subsection{Ongoing and Further Work}

Work is ongoing to extend and further develop the capacity utilisation and CRRD datasets, and continue the investigation of the relationships between them. As well as providing some useful and interesting results, the work to date has shown that the analysis of individual stations and junctions can be quite laborious and time-consuming. Of necessity, the capacity utilisation calculation process requires the development of a model representation of each station (or junction) node, but this model can then be used repeatedly for the analysis of different timetable options and time periods. The same is not necessarily true of delay records, however (in cases where the same train gets delayed at the same location on different days, an assignment can be re-used, but the initial assignment must be made, recorded and subsequently matched to enable this to be done).

For relatively simple instances, two-track stations, for example, where trains travelling in one direction use one track/platform and trains travelling in the opposite direction use the other, delays can be assigned semi-manually by direction in a relatively quick and straightforward manner. However, as in the case of Peterborough, when there are multiple track and platform options in a single direction, and a wide range of train types (freight, as well as long-distance, commuter and regional passenger services), origins and destinations, the assignment of delays to individual tracks, platforms and switches requires much more attention and processing time. Work is therefore underway to develop the means of processing the delay records and assigning them automatically to the appropriate tracks and/or platforms of station and junction nodes. This will assist with the development of a larger dataset, both geographically and temporally, and will allow the rapid assignment to the network of additional Periodic (i.e. four-week) delay datasets as they become available on Network Rail's website. 
An important element of the work is the identification of appropriate upper limits for capacity utilisation at stations and junctions, beyond which acceptable levels of performance are unlikely. One approach already taken considers the trade-off between the economic benefits of additional train services and the disbenefits associated with increased levels of delay (Preston et al., 2015). This and potential alternative approaches will be considered and investigated further.

The ongoing reliance in Britain's railway industry upon empirical data and relationships (in conjunction with the use of simulation) has already been noted. Looking beyond the calculation and assignment of CUI and related CRRD data to investigate and develop the relationships between capacity utilisation and performance on the nodes and links of the railway network, it would be useful to investigate the application of established methods like the use of max-plus algebra to the assessment of timetable stability in Britain. It would be particularly helpful to develop such models and compare their results and predictions with the historical performance data whose analysis is described above, and this is the objective of planned further work in this area.

This further work will be undertaken in the context of the Office of Rail and Road's (ORR's) forthcoming 2018 Periodic Review (PR18) of Britain's railways (ORR, 2016). The review will include funding levels, performance targets and the recalibration of various measures, potentially including the Capacity Charge, to which some of the work undertaken for the DITTO Rail Systems project is likely to be applicable.

\section{Conclusions}

The modelling and analysis described above builds upon previous work to provide extended and improved knowledge and understanding of the relationships between capacity utilisation and performance (i.e. delay) at railway stations and (potentially) junctions. The updating of the capacity utilisation calculation methods and tools has produced encouraging results, and will be developed and implemented further during the remaining duration of the DITTO Rail Systems project, and for wider analytical purposes, potentially including aspects of PR18.

The additional empirical data on the relationship between capacity utilisation and performance helps to indicate the extent to which services may be added to existing timetables without introducing unacceptable performance risks, thus helping to identify indicative upper limits for capacity utilisation at network nodes, similar to those already established for the links between nodes. As well as addressing some of the issues and questions raised by the second edition of UIC 406, this is of general relevance in the widespread quest to maximise railway capacity while maintaining reliably acceptable levels of performance.

As part of a wider effort to develop improved understanding of the relationships involved, the results generated also provide a dataset which may be used to investigate and, ideally, validate the application in Britain of existing timetable stability analysis approaches such as the use of max-plus algebra. Success in this area could help to persuade a somewhat conservative and sceptical industry of the merits and potential benefits, already proven elsewhere, of such approaches. 


\section{References}

Armstrong, J., Blainey, S. Preston, J., Hood, I., 2011. "Developing a CUI-based Approach to Network Capacity Assessment”, In: Proceedings of the 4th International Seminar on Railway Operations Modelling and Analysis, Rome, Italy.

Armstrong, J., Preston, J., Potts, C., Paraskevopoulos, D., Bektas, T., 2012. "Scheduling Trains to Maximise Railway Junction and Station Capacity", In: Proceedings of the Conference on Advanced Systems in Public Transport 2012 (CASPT2012), Santiago, Chile.

Arup, 2013. Recalibrating the Capacity Charge for CP5 [online]. Available from http://www.networkrail.co.uk/WorkArea/DownloadAsset.aspx?id=30064786027\&cd=2 [Accessed 28 November 2016].

Capgemini, 2013. The future of the railway [online]. Available from http://www.uk.capgemini.com/blog/business-analytics-blog/2013/02/the-future-of-therailway [Accessed 25 November 2016].

DfT, 2012. High-speed rail: Investing in Britain's future - decisions and next steps [online]. Available from https://www.gov.uk/government/publications/high-speed-rail-investingin-britains-future-decisions-and-next-steps [Accessed 25 November 2016].

Gibson, S., Cooper, G., Ball, B., 2002. "Developments in Transport Policy: The Evolution of Capacity Charges on the UK Rail Network", Journal of Transport Economics and Policy 36 (2), 341-354.

Goverde, R.M.P., 2015. “Timetable Stability Analysis”, In: Hansen, I.A., Pachl, J. (eds.), Railway Timetabling \& Operations: Analysis, Modelling, Optimisation, Simulation, Performance Evaluation pp. 133-153, Eurail Press, Hamburg.

Haith, J, Johnson, D. and Nash, C., 2014. "The Case for Space: The Measurement of Capacity Usage, its Relationship with Reactionary Delay and the Calculation of the Congestion Charge on the British Rail Network", Transportation Planning and Technology, 37, 1, 20-37.

Huber, H.-P., Herbacek, R., 2013. "UIC Leaflet 406 - Capacity, New Release 2012”, In: Proceedings of the World Congress on Railway Research 2013 (WCRR 2013), Sydney, Australia.

Landex, A., 2011. "Station Capacity", In: Proceedings of the 4th International Seminar on Railway Operations Modelling and Analysis, Rome, Italy.

Libardo, A., Pellegrini, P., Salerno, G., 2011. "Capacity in Railway Junctions and Optimal Route Management", In: Proceedings of the 4th International Seminar on Railway Operations Modelling and Analysis, Rome, Italy.

Martin, U., 2015. "Performance Evaluation", In: Railway Timetabling and Operations (eds. Hansen, IA; Pachl, J). Eurail Press, Hamburg.

Mussone, L., Calvo, L., 2013. "An analytical approach to calculate the capacity of a railway system”, European Journal of Operational Research, 228, 11-23.

Network Rail, 2016. Operational Rules [online]. Available from http://www.networkrail.co.uk/aspx/3741.aspx [Accessed 28 November 2016]

OECD, 2013. Recent Developments in Rail Transportation Services [online]. Available from http://www.oecd.org/daf/competition/Rail-transportation-Services-2013.pdf [Accessed 25 November 2016].

ORR, 2016. 2018 periodic review of Network Rail (PR18) [online]. Available from http://orr.gov.uk/ data/assets/pdf_file/0009/21996/pr18-initial-consultation-documentmay-2016.pdf [accessed 23 November 2016]

Pachl, J., 2009. Railway Operation \& Control. VTD Rail Publishing, Mountlake Terrace. 
Pachl, J., 2015. “Timetable Design Principles”, In: Railway Timetabling and Operations (eds. Hansen, IA; Pachl, J). Eurail Press, Hamburg.

Preston, J., James, P., Kovacs, A, Ye, H., 2017. "Developing Integrated Tools to Optimise Railway Systems: An Overview", In: Proceedings of the 7th International Conference on Railway Operations Modelling and Analysis (RailLille2017), Lille, France.

Preston, J., Kampantaidis, G., Armstrong, J., 2015. "The Trade-Offs between Delays and Capacity Utilisation: Observations from the UK", In: Proceedings of the 6th International Conference on Railway Operations Modelling and Analysis (RailTokyo2015), Tokyo, Japan.

UIC, 2004. Leaflet 406: Capacity. UIC, Paris.

UIC, 2013. Leaflet 406: Capacity ( $2^{\text {nd }}$ edition). UIC, Paris.

Vromans, M., 2005). "Reliability of a Railway System", PhD Thesis. Erasmus University, Rotterdam, Netherlands. 